\title{
Clinical correlates of epistaxis management in ENT
} emergency

Received: 08 April, 2020

Accepted: 13 April, 2020

Published: 14 April, 2020

*Corresponding author: Dr. Vivek Kumar, Flat no 3, block no 15, Adalatganj, Buddha Marg, Patna, Bihar, India, Pin: 800001; Mob: +91 7782923909; Phone: +910612 2237215 E-mail: drvkumarent@gmail.com

Keywords: Epistaxis; Endoscopy; Hemostasis

https://www.peertechz.com

\section{Vivek Kumar*, Badal Kumar, Naresh Chandra Sharma}

Department of E.N.T, Patna Medical College Hospital, Flat No. 3, Block No. 15, Adalatganj, Buddha Check for updates

\section{Abstract \\ Introduction: Epistaxis is a frequent condition encountered in an ENT emergency which causes severe anxiety to the patient. Management of epistaxis may become challenging and can necessitate urgent intervention.}

Objective: To analyze the clinical correlates of nasal bleeding in an ENT emergency setting

Type of study: Retrospective study.

Materials and methods: Data was collected from the ENT emergency register, ward registers and case notes of patients presenting with nasal bleeding to the emergency at an urban tertiary health care center in India for a period of 1 year. Data acquired was reviewed and statistically interpreted and presented in graphical and descriptive formats.

Results: We encountered 204 cases of epistaxis in the ENT emergency over the period under study. Cardiovascular complaints (hypertension and atherosclerosis) were the commonest causes of nasal bleeding in the study population. There was a seasonal preponderance for winter months. Significant correlation was observed between the site of bleeding and the management accorded to the patient. Advances in endoscopic facility and imaging modalities contributed immensely to the management.

Conclusion: Epistaxis management protocol should be based on etiology, age, site and severity of nasal bleeding and in accordance with facilities available at the centre. Active and meticulous search for cause of nasal bleeding should be performed. Training of residents in conservative treatment approaches should be done under proper guidance.

\section{Introduction}

Epistaxis is defined as bleeding from the nose [1]. The term epistaxis was coined by William Cullen. Historically, this condition has been known to mankind since early times. The simplest and familiar "Hippocratic Technique" of pinching the ala nasi to control bleeding is well mentioned in literature. Morgagni, in his writings about epistaxis even predicted endoscopy in $18^{\text {th }}$ century [2]. Epistaxis or nasal bleeding is a common emergency condition routinely faced by otorhinolaryngologists throughout the world which necessitates prompt intervention to reduce morbidity and prevent mortality. Though the global incidence is difficultto ascertain, it is believed to affect $7-14 \%$ of adult population in their lifetime [3].
Epistaxis can present with varied etiologies, with contributions from both local and systemic factors. Several other factors like age, sex, weather and site of bleeding have been shown to associatestrongly with epistaxis. Treatment modalities generally tend to progress from non invasive conventional methods to more invasive procedures. Though most of the patients respond to prompt and appropriate intervention by first attending physician, a small proportion especially the elderly require hospital admission [4]. Identification of the site of bleeding is a vital determinant of epistaxis management and advancements in endoscopic and radiological modality have aided this aspect of management protocol.

There is a marked variation in presentation, causations, investigation profiles and treatment preferences at different 
centers. There are scopes for controversies and non standardized practice persists. This situation needs to be dealt with in an evidence based fashion.This article attempts to discuss riskfactors associated with epistaxis and critically scrutinizeand evaluate the pathway of management based onthe higher level of evidence available.

\section{Material and methods}

This retrospective descriptive observational study was conducted at Patna Medical College and Hospital which is a tertiary care referral hospital cum teaching institute situated in the district of Patna, India. Records were collected from the emergency register of the otorhinolaryngology wards for a period of 1 year. This included the entire group of patient seen or admitted in ENT emergency ward that were treated for nasal bleeding in this period. The data collected included the demographics (age, gender), history of other concurrent illness, medications and pathologies with hemorrhagic risk, similar episodes of epistaxis (any prior incident over previous 6 months, nasal procedures or surgeries).The treatment protocol includes recording of vitals parameters, clinical examination, amount (copious or non copious) and pattern (continuous or discontinuous) of nasal bleed, initial stabilization and if required, resuscitation of the patient. Initial maneuvers comprised of head posture, suction of clot, use of vasoconstrictor and local procedures like bidigital pressure, chemical cauterization and anterior nasal packing. Surgical management like endoscopic sinus surgery and open surgery if required were done according to the severity and pathology of epistaxis. The required investigations and diagnostic procedures for evaluation like diagnostic nasal endoscopy and radiological investigations were carried out subsequently as indicated. Management of epistaxis was accomplished in a stepwise approach.

The records collected were utilized to retrieve admission records and case notes from medical records department which were reviewed in totality. The data collected was statistically interpreted and presented in tabular and descriptive formats.

\section{Results}

A total of 621 patients were treated in the ENT emergency in a period of 365 days. Out of these, 204 patients presented with chief complaints of nasal bleeding. Epistaxis constituted 32.85 $\%$ of total emergency cases. Out of these $66.66(\%)$ were male and $33.33(\%)$ were female patients in a ratio of 2:1. The age of patients ranged from 2 years to 90 years with a mean age 42.52 years. Maximum incidence was observed in age group of 5160 years. Table 1 gives the age distribution pattern of patients presenting with epistaxis.

Monthly variation of nasal bleeding was noted and tabulated in month wise categories (Table 2). Maximum incidence of epistaxis was observed in winter months. $57.35 \%$ of cases were observed in winter months of the year (Table 2). Most of the cases 168 cases $(82.35 \%)$ were anterior nasal bleed whereas 36 cases $17.65 \%$ presented with posterior nasal bleeding. The discrimination between anterior and posterior was in relation to the pyriform aperture of the nose [1].
Table 1: Age and Sex Distribution.

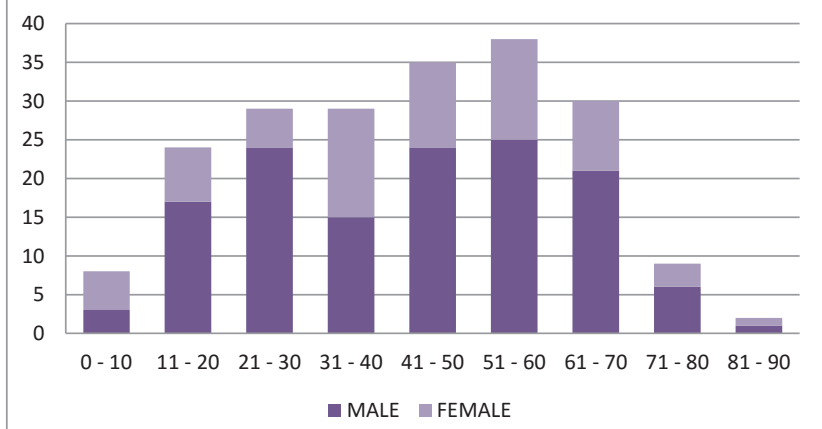

Table 2: Monthly Variation of Etiologies of Epistaxis.

\begin{tabular}{|c|c|c|c|c|c|c|}
\hline & $\begin{array}{c}\text { JAN- } \\
\text { FEB }\end{array}$ & $\begin{array}{c}\text { MAR- } \\
\text { APR }\end{array}$ & $\begin{array}{c}\text { MAY- } \\
\text { JUN }\end{array}$ & $\begin{array}{c}\text { JUL- } \\
\text { AUG }\end{array}$ & $\begin{array}{c}\text { SEP- } \\
\text { OCT }\end{array}$ & $\begin{array}{c}\text { NOV- } \\
\text { DEC }\end{array}$ \\
\hline Trauma (Injury+Surgery) & 7 & 6 & 5 & 6 & 8 & 7 \\
\hline $\begin{array}{c}\text { CVS } \\
\text { (Hypertension+Atherosclerosis) }\end{array}$ & 14 & 11 & 7 & 7 & 8 & 10 \\
\hline Idiopathic & 3 & 4 & 2 & 1 & 2 & 4 \\
\hline Chronic Rhinosinusitis & 4 & 5 & 1 & 2 & 2 & 3 \\
\hline Foreign Body & 1 & 1 & 1 & 2 & 1 & 1 \\
\hline Tumor (Benign + Malignant) & 1 & 3 & 3 & 2 & 5 & 3 \\
\hline Blood Dyscrasia & 2 & 1 & 2 & 1 & 0 & 0 \\
\hline Maggot & 4 & 2 & 10 & 1 & 3 & 7 \\
\hline Deviatednasal Septum & 3 & 3 & 3 & 2 & 0 & 4 \\
\hline Drug Induced & 1 & 1 & 0 & 0 & 0 & 1 \\
\hline Total & 40 & 37 & 34 & 24 & 29 & 40 \\
\hline
\end{tabular}

Cardiovascular complaints $27.94 \%$, mainly hypertension were the leading cause of nasal bleeding in our study. Hypertensive epistaxis was primarily seen in aged individual most of who were already on antihypertensive medication. Trauma $19.11 \%$ followed as next leading cause and included iatrogenic, fingernail trauma, direct physical trauma and road traffic accidents. Fingernail trauma was foremost cause of epistaxis in pediatric patients and male patients constituted the bulk of traumatic nasal bleed. Trauma was followed by maggot infestation (13.23\%) of the nose and paranasal sinuses. Myiasis typically occurred in geriatric age group and reflected the poor socioeconomic status of the population demography of the patients served by the institution. Nasal pathologies such as deviated nasal septum, spur, rhino sinusitis and nasal malignancies added up to a quarter of overall epistaxis cases. Nasal foreign bodies, blood dyscrasias and drug induced nasal bleeding were other causes of epistaxis encountered in our study. Some rare cases like nasal bleeding in a kalaazar (leishmaniasis) patient, dengue fever and pregnant lady without history of eclampsia were also seen during the course of study.

Those cases where no definite source or cause of epistaxis could be ascertained in spite of a comprehensive search that included detailed history taking, clinical examination, hematological investigations, endoscopic assessment and assistance of radiological imaging modalities, were categorized 
as idiopathic epistaxis. This category comprised of 7.84\% [16] cases in our study. Table 3 depicts the various etiologies of epistaxis seen during the course of our study.

The management of epistaxis was done according to the presentation and generally preceded from conservative to more invasive procedures (Table 3). Digital pressure, local and general haemostatic agents like tranexemic acid and sufficient rest formed the mainstay of conservative management. Minor bleeding like fingernail trauma was satisfactorily treated with conservative management in $5.39 \%$ of cases. Anterior nasal packing formed the mainstay of treatment in majority of cases (55.39\%). Refractory cases where anterior nasal packing and haemostatic medications were unable was unable to control the nasal bleed, were managed by posterior nasal packing (15.19\%). Surgical intervention was reserved for cases where initial management could not prevent recurrence of surgery. It included local electrocautery (10.29\%), arterial ligation $(1.96 \%)$ of sphenopalatine, internal maxillary and carotid artery ligation.

Table 3: Treatment Modalities Adopted for Epistaxis Management

\begin{tabular}{|c|c|c|}
\hline Treatment Modality & Frequency & Percentage \\
\hline Non surgical & & \\
\hline Conservative & 11 & 5.39 \\
\hline Local cauterization & 23 & 11.27 \\
\hline Anterior packing & 113 & 55.39 \\
\hline Posterior packing & 31 & 15.19 \\
\hline Surgical & & \\
\hline Local electrocautery & 21 & 10.29 \\
\hline SPA ligation & 4 & 1.96 \\
\hline Other surgeries & 1 & 0.49 \\
\hline
\end{tabular}

\section{Discussion}

Nasal bleeding is a common condition encountered in the emergency which causes grave anxiety to the patients. Troublesome nasal bleeding however is a demanding scenario and can have grievous consequences. Multiple etiologies and absence of fixed management protocols leads to dissimilar strategies adopted by rhinologists around the world. The management of epistaxis comprises a wide range of planning and treatment alternatives so it is imperative to understand when to correctly employ each individual intervention.

The age distribution pattern of epistaxis has shown variability across different studies. The concept of bimodal age distribution of epistaxis is available where epistaxis is commoner in young adults and in geriatric population [5]. Western literature however has multiple studies categorizing epistaxis as a disease of the old with significant occurrence in over 60 years of age $[6,7]$. Our study observed a considerable occurrence of young male patients most of which were incidence of traumatic epistaxis apart from an increased incidence in old age. Nose pricking injury to the Kiesselbach's plexus in anterior nasal cavity in children is a familiar complaint in ENT emergency. Geriatric epistaxis is assumed to be prone to more severe nosebleed than young population due to loss of elastic and contractile property in their arteries [8]. Most studies including ours show a male preponderance of nasal bleeding cases [9]. Seasonal variation of epistaxis has been underlined in numerous studies most of which have shown an increased incidence in winter months [10]. Similar results were observed in this study as winter months had a greater part of nasal bleeding cases. High wind velocity and dryness causing crust formation in the nostrils may predispose to bleeding during winters.

The list of etiologies for epistaxis is a comprehensive one with several broad categories and subcategories and the frequency varies in different series around the world. Hypertensive epistaxis was the commonest cause of nasal bleeding encountered at our centre. It reflects poor blood pressure control among the individuals [11]. Epistaxis as the presenting complaints for previously undiagnosed hypertensive cases were also seen during the period of study. Neto et al suggested enlargement of blood vessels in nasal mucosa due to degeneration of vessel wall in hypertension makes them prone for bleeding [8]. Recurrence was frequent in hypertensive nasal bleed particularly in geriatric population. We recommended reevaluation of hypertensive status, regular check up and monitoring of co morbidities in these patients. A casual relationship between hypertension and epistaxis however has been denied by multiple large studies [12]. Traumatic nasal bleed, more often than not is seen in adult male patients [13]. The prominence of nose makes it vulnerable for injury. Road traffic accidents, contact sports and other maxillofacial injuries all result in epistaxis and management should be tailored as per the presentation. Nasal pathologies like rhinosinusitis, nasal and paranasal tumors and even a septal spur may lead to epistaxis. Angiofibromas, hemagiopericytomas and malignancies are known to present with epistaxis as the primary symptoms. Nasal myiasis, prevalent in tropical and under developed countries is infestation of nasal cavity with maggots [14]. Invasion of surrounding necrotic tissue and blood vessels results in nasal bleeding [15]. Our institute caters to a large number of patients from poor socioeconomic stratum of the society which elucidates the raised level of myiasis patients. Blood dyscrasias, altered liver function status. Coagulopathies, anticoagulant therapy are causes of nasal bleeding that routinely present in emergency and demand a thorough history of the patient from the attending physician. Idiopathic epistaxis i.e. nasal bleed without an apparent cause is a topic of much disagreement. There have been reports of over reporting of idiopathic cases in multiple series. This could be due to limitation of diagnostic modalities and intervention required for proper etiological assessment. Therefore, a meticulous search for the cause and source of bleeding should be carried out. The decision to brand an episode of epistaxis as idiopathic should be reserved for cases where a comprehensive assessment has been made. The assessment protocol must includeendoscopic assessment and radiological modalities along with hematological investigations for infrequent systemic disorders. 
The management of epistaxis includes a variety of approaches and management options. It becomes the onus of the rhinologist to appreciate when and how to utilize the option available. Reassuring the patient, monitoring the vital parameters, quick initial overall assessment and swift enquiry about relevant history should be done by primary caregiver. As a significant number of cases are self limiting, conservative management is often sufficient first line of therapy. Topical nasal decongestants like oxymetazoline have been shown to be successful in treating epistaxis [16]. Role of tranexemic acid used topically or orally has been contentious and opinions show a discrepancy for different researchers [17]. Cauterisation by silver nitrate or electrocautery of the nasal mucosa; by anterior rhinoscopy or by using endoscope, in a non acute situation is an effective, cheap and easy to perform technique of epistaxis control $[18,19]$.

Anterior nasal packing is the mainstay of epistaxis management in most series and it consists of placement of an intranasal apparatus that applies constant local pressure to the surrounding structures. Nasal packing works by direct pressure, consequent reduction of mucosal irritation and clot formation surrounding the foreign body, which enhances pressuredecreases bleeding.The nasal packs are left in situ for between $24-72$ hours [20]. Ribbon gauze soaked in petroleum jelly, vaseline or bismuth iodine paraffin paste is the traditional method which is nowadays superseded by special tampons (Merocel, Rapid Rhino and Kaltostat) and balloon catheters (Brighton or Epistat). Posterior nasal packing that comprises of compression in posterior choana area is generally performed with Foley urethral catheter inflated with up to $15 \mathrm{ml}$ of saline. However, posterior nasal packing causes considerable pain, edema and other complications; hence they should only be used in refractory cases. Insertion of nasal pack can however lead to a plethora of complications and unpleasant effects. Sinusitis, septal perforation, abscess formation, alar necrosis, eustachian tube dysfunction, vasovagal attack during insertion, traumatic insertion with injury to surrounding structure have been noted. The severe complication are fortunately rare, but reports of cardiopulmonary dysfunction, toxic shock syndrome, infective endocarditis [21], myocardial infarction and life threatening upper airway obstruction [22] due to dislodgement of nasal pack have been reported in literature. Success of nasal packing can be assessed only after removal of the pack. The concurrent use of antibiotic prophylaxis with nasal packing is generally practiced [23], but the evidence base for this is lacking.

Failure of posterior nasal packing requires application of surgical intervention to control nasal bleeding. Ligation of the blood vessels is done based on a solid knowledge of vascular supply of nose and should be performed in closest possible proximity of the source of bleeding. Hence the recommended hierarchy of ligation is sphenopalatine artery followed by internal maxillary, external carotid and anterior/posterior ethmoid artery [1].The development of ESPAL (Endoscopic Ligation of Sphenopalatine Artery) has been a revolutionary method for epistaxis control since its introduction over two decades ago [24]. It conforms to the idea to controlling the bleed as close as possible to the source and yet maintain a sufficiently distal area to the bleed. Maxilliary artery ligation described way back in 1965 [25], has recently lost its popularity due to its invasive approach and potential complications. Ligation of external carotid and the ethmoid arteries are not very routinely performed these days in ENT emergencies. Recent studies have shown earlier intervention with endoscopic surgical techniques is better suited to manage epistaxis than conventional approaches due to its high success rate, low risks and cost effectiveness. There has also been a recent focus on embolisation procedures as better initial option in patients unfit for general anesthesia, anticoagulation therapy and in surgical failures [26].

Thus, the treatment options available for management of epistaxis are multiple and require different levels of expertise. Recent surveys show that there is still poor understanding of initial management of epistaxis among junior doctors [27]. It becomes imperative for the treating rhinologists to decide the utility and adequacy of different options as per the demand of the situation. Various flowcharts and algorithms have been suggested by different centers around the world to outline a standard protocol for management of epistaxis. The protocol adopted by each centre should confirm to limitations of personnel and resources available at the institution. A systemic approach to management of nasal bleeding can go a long way in averting disastrous sequel of epistaxis.

\section{Limitations}

Our study, being a single centre study suffers from being limited by institutional protocols regarding treatment modality and diagnostic interventions. Epistaxis being a common entity all over the globe has variations in ethnicity, cultural practices and availability of diagnostic and treatment modality. Thus, a multicentre study with sharing of information and knowledge would be more suitable to attain the purpose of such a study.

\section{Conclusion}

The management of nasal bleeding with a standardized approach is vital for favorable outcome in emergency situations. Ascertaining the etiology of epistaxis and locating the source of bleeding must be done meticulously. Nasal packing is a reliable and adequate treatment option for majority of cases Endoscopic surgical technique for epistaxis control requires good knowledge of vascular supply of the nose. Every centre should have a management protocol for epistaxis for proper standardization and evidence based treatment.

\section{References}

1. McGarrygw (2008) Epistaxis. In Michael Gleeson Ed. Scott Brown's otolaryngology $7^{\text {th }}$ Edition London: Hodder Arnold publication 2: 1603-1608.

2. Morgagni JP (1983) The seats and causes of diseases. Alabama; Gryphon Editions Ltd 1: 312-54 (first published in 1761)

3. Weiss NS (1972) Relation of high blood pressure to headache, epistaxis and selected other symptoms. N Engl J Med 287: 631-633. Link: https://bit.ly/3ekIFOH

4. Melia L, Mc Garry GW (2011) Epistaxis: update on management. Curr Opin Otolaryngol Head Neck Surg 19: 30-35. Link: https://bit.ly/2V3LiMh 
5. Hussain G, Iqbal M, Shah SA, Said M, Sanaulla H, et al. (2006) Evaluation of aetiology and efficacy of management protocol of epistaxis. J Ayub Med Coll Abbottabad 18: 63-66. Link: https://bit.ly/2xhHRIS

6. Pallin DJ, Chang Y, Mc Kay MP, Emond JA, Pelletier AJ, et al. (2005) Epidemiology of epistaxis in USA emergency departments, 1992 to 2001. Ann Emerg Med 46: 77-81. Link: https://bit.ly/3b67A5A

7. Walker TWM, Caefarlane TV, Mc Garry GW (2007) The epidemiology and chronobiology of epistaxis: aninvestigation of Scottish hospital admission 1995-2004. Clin Otolaryngol 32: 361-365. Link: https://bit.ly/2KcHSkd

8. Neto JFL, Fuchs FD, Facco SR, Gus M, Fusolo L, et al. (2009) Is Epistaxis Evidence of End Organ Damage in patients with Hypertension. Laryngoscope 109: 1111-1115. Link: https://bit.ly/2VsB2fD

9. Gilyoma JM, Chalya PL (2011) Etiological profile and treatment outcome of epistaxis at a tertiary care hospital in Northwestern Tanzania: a prospective review of 104 cases. BMC Ear Nose Throat Disord 11: 8. Link: https://bit.ly/3b8e4ky

10. Wormald PJ (2006) Epistaxis. Byron and Bailey's Head and Neck Surgery Otolaryngology. $4^{\text {th }}$ ed. Philadelphia; Lippincott Williams and Wilkins 505-514

11. Glioma JM, Chaya PL (2011) Etiological profile and treatment outcome of epistaxis at a tertiary hospital in Northwestern Tanzania; a prospective review of 104 cases. BMC Ear Nose Throat Disord 11: 8. Link: https://bit.ly/34xQ2Ng

12. Lubianca-Neto JF, Bredemeier M, Carvalhal EF, Arruda CA, Estrella E, et al. (1998) A study of the association between epistaxis and severity of hypertension. Am J Rhinol 12: 269-272. Link: https://bit.ly/3cbV2K4

13. Gilyoma JM, Chalya PL (2011) Etiological profile and treatment outcome of epistaxis at a tertiary care hospital in Northwestern Tanzania: a prospective review of 104 cases. BMC ear nose Throat disord 11:8. https://bit.ly/34wVKih

14. Franza R, Leo L, Minerva T, Sanapo F (2006) Myiasis of the tracheostomy wound: Case report. Acta Otorhinolaryngol Ital 26: 222-224. Link: https://bit.ly/3ceQW40

15. Thomas S, Nair P, Hegde K, Kulkarni A (2010) Nasal myiasis with orbital and palatal complications. BMJ Case Rep 2010. pii: bcr0820103219. Link: https://bit.ly/3efCJW8

16. Krempel GA, Noorthy AD (1995) Use of oxymetazoline in the management of epistaxis. Ann Otol Rhinol Laryngol 9: 704-706. Link: https://bit.ly/2wzeyB0

17. White A, O'Reilly BF (1988) Oral tranexamic acid in the management of epistaxis. Clin Otolaryngol Allied Sci 13: 11-16. Link: https://bit.ly/2JWKVN4

18. Pope LE, Hobbs CG (2005) Epistaxis: An update on current management Postgrad Med J 81: 309-314. Link: https://bit.ly/2XsbeTr

19. Vis $E$, van den Berge $H(2011)$ Treatment of epistaxis without the use of nasal packing, a patient study. Rhinology 49: 600-604. Link: https://bit.ly/2XtXZBC

20. Tan LKS, Calhoun KH (1999) Epistaxis. Med Clin North Am 83: 43-56. Link: https://bit.ly/2Vo5tmT

21. Simmen DB, Raghavan U, Briner HR, Manestar M, Groscurth P, et al. (2006) The anatomy of the sphenopalatine artery for the endoscopic sinus surgeon. Am J Rhinol 20: 502-505. Link: https://bit.ly/2K0QdHn

22. Middleton PM (2004) Epistaxis. Emergency Medicine Australasia 16: 428-440. Link: https://bit.ly/3b9ud9e

23. Biswas D, Wilson H, Mal R (2006) Use of systemic prophylactic antibiotics with anterior nasal packing in England, UK. Clin Otolaryngol 31: 566-567. Link: https://bit.ly/2Xu6RXN

24. Budrovich R, Saetti R (1992) Microscopic and endoscopic ligature of the sphenopalatine arter. Laryngoscope 102: 1391-1394. Link: https://bit.ly/2XsbKk

25. Chandler JR, Serrins AJ (1965) Transantral ligation of the internal maxillary artery for epistaxis. Laryngoscope 75:1151-1159. Link: https://bit.ly/2XxWeDh

26. Rudmik L, Smith TL (2012) Management of intractable spontaneous epistaxis Am J Rhinol Allergy 26: 55-60. Link: https://bit.ly/3b03GLv

27. Fox R, Nash R, Lui ZW, Singh A (2016) Epistaxis management: current understanding amongst junior doctors. J Laryngol Otol 130: 252-255. Link: https://bit.ly/3egEYs9

\section{Discover a bigger Impact and Visibility of your article publication with}

Peertechz Publications

Highlights

* Signatory publisher of ORCID

* Signatory Publisher of DORA (San Francisco Declaration on Research Assessment)

* Articles archived in worlds' renowned service providers such as Portico, CNKI, AGRIS, TDNet, Base (Bielefeld University Library), CrossRef, Scilit, J-Gate etc.

* Journals indexed in ICMJE, SHERPA/ROMEO, Google Scholar etc.

* OAI-PMH (Open Archives Initiative Protocol for Metadata Harvesting)

- Dedicated Editorial Board for every journal

* Accurate and rapid peer-review process

* Increased citations of published articles through promotions

* Reduced timeline for article publication

Submit your articles and experience a new surge in publication services (https://www.peertechz.com/submission).

Peertechz journals wishes everlasting success in your every endeavours.

Copyright: ( $) 2020$ Kumar V. This is an open-access article distributed under the terms of the Creative Commons Attribution License, which permits unrestricted use, distribution, and reproduction in any medium, provided the original author and source are credited. 